\title{
Comparison of Digestion Methods for Atomic Absorption Analysis of Food Materials
}

\author{
Kazuyoshi TAKIYAMA and Yuuko IsHII \\ Department of Home Science, Mukogawa Women's University, Ikebirakicho, Nishinomiya 663, Japan
}

\begin{abstract}
Digestion (ashing) methods for atomic absorption spectrometric determination of metallic components in foods were investigated. Four ashing methods were employed: the dry ashing using a crucible and a gas burner, the wet ashing in beaker heated on a hot plate, the wet ashing heated in commercial microwave ovens and the wet ashing heated by the irradiation with extreme infrared (IR) light. The best ashing method was the IR method.
\end{abstract}

Keywords Food materials, dry ashing, wet ashing, atomic absorption spectroscopy

Generally, foods are ashed at $550^{\circ} \mathrm{C}$ to determine minerals, such as calcium, phosphorous, iron, sodium and potassium. ${ }^{1,2}$ The dry ashing is convenient to determine these elements, but the loss of some volatile elements during the ashing has been reported. ${ }^{3,4}$ The wet ashing is also applied to food materials ${ }^{2 \sim 5}$. In this paper, several ashing methods for the determination of minerals in foods by atomic absorption spectrometry (AAS) are described.

\section{Experimental}

\section{Pretreatment of food materials}

Food materials were pulverized before ashing. Each dried specimen was pulverized by a mortar. Each vegetable was cut into small pieces with a knife; meat was pulverized with a cooking blender.

\section{Dry ashing in a crucible}

Dry ashing of each food sample was carried out in a crucible by heating with a gas burner or in an electric furnace.

\section{Wet ashing}

The wet ashing methods are summarized in Table 1. The detailed procedures are as follows.

Wet ashing in a tall beaker. The wet ashing of foods in a tall beaker was carried out by heating on a plate. The digestion reagents used for $10 \mathrm{~g}$ of a food were a mixture of nitric acid $(14.5 \mathrm{M}, 20 \mathrm{ml})$ and hydrogen peroxide $(30 \%, 20 \mathrm{ml})$ or a mixture of nitric acid $(15.5 \mathrm{M}, 20 \mathrm{ml})$ and perchloric acid $(60 \%, 4 \mathrm{ml})$. The decomposition temperature for ashing was 60 to $70^{\circ} \mathrm{C}$ to prevent the

This paper was presented at the Kitami Conference of ICAS '91. solution from splattering by boiling. Wet ashing by heating with microwave: A Quick Digester QD-1 (2450 $\mathrm{MHz}, 700 \mathrm{~W}$, Mitsubishi Chemical Co.) was used. A 5 or $10 \mathrm{~g}$ aliquot of a food sample was taken into an ashing bottle made of borosilicate glass; then a mixture of nitric acid $(14.5 \mathrm{M}, 5$ to $20 \mathrm{ml})$ and perchloric acid $(60 \%, 1$ to $8 \mathrm{ml})$ or a mixture of nitric acid $(14.5 \mathrm{M}, 10$ to $15 \mathrm{ml})$ and hydrogen peroxide $(30 \%, 10$ to $15 \mathrm{ml})$ was added into the bottle. The sample was digested for $60 \mathrm{~min}$ in the digester. The color of the solution turned to brown and then the solution became transparent. After solution was heated to dryness, the white residue was dissolved in water and diluted to 20 or $50 \mathrm{ml}$.

Another microwave ashing was performed by use of a Microwave Digestion Floyd RMS-150 (Prolabo). Less than $0.5 \mathrm{~g}$ of dry sample or $1 \mathrm{~g}$ of wet sample was taken into a Teflon bottle and $5 \mathrm{ml}$ of $14.5 \mathrm{M}$ nitric acid and $1 \mathrm{ml}$ of $30 \%$ hydrogen peroxide were added into the bottle. The sample was digested by microwave irradiation under $15 \mathrm{~atm}$ for $15 \mathrm{~min}$. After cooling of the bottle, the solution was neutralized and diluted with water to $20 \mathrm{ml}$.

Wet ashing by heating with extreme IR light. A Digesdahl 20 (Hach Co.) was used to digest several food samples. A 3 to $5 \mathrm{~g}$ aliquot of a wet sample or a less than $0.5 \mathrm{~g}$ aliquot of a dry sample was taken into a $100 \mathrm{ml}$ decomposition flask. After $4 \mathrm{ml}$ of concentrated sulfuric acid was added, the flask was connected with a condenser and a capillary funnel. Then the flask was placed on the plate, which was preheated at $440^{\circ} \mathrm{C}$ by the extreme IR light irradiation. After irradiation for 2 to $5 \mathrm{~min}$, the sample was carbonized until the color of the solution changed to black. Then $30 \%$ hydrogen peroxide was added into the flask through the funnel at $0.5 \mathrm{ml} / \mathrm{min}$ for $20 \mathrm{~min}$. After the solution became colorless and transparent, the heating was continued for $1-2 \mathrm{~min}$; then the solution was cooled on a porcelain plate. The cooled 
solution was neutralized and diluted with water to 20 or $50 \mathrm{ml}$.

Wet ashing in a Teflon crucible. The food material was dried at $100^{\circ} \mathrm{C}$ and ground. A sample weighing from 0.3 to $0.5 \mathrm{~g}$ was taken into a Teflon crucible (Uni-seal Decomposition Vessels Ltd.) and $5 \mathrm{ml}$ of $14.5 \mathrm{M}$ nitric acid and 1 to $2 \mathrm{ml}$ of $60 \%$ perchloric acid were added into the crucible. The crucible was covered with a Teflon sealing disk and closed in a metal vessel. The crucible was heated at $100^{\circ} \mathrm{C}$ for $1 \mathrm{~h}$. After the vesel was cooled, the decomposed sample was transferred into a $20 \mathrm{ml}$ volumetric flask.

Atomic absorption measurements of all sample solutions described above were made at $324.7 \mathrm{~nm}$ for $\mathrm{Cu}$, $307.9 \mathrm{~nm}$ for $\mathrm{Zn}$ and $248.3 \mathrm{~nm}$ for $\mathrm{Fe}$ by use of a graphite furnace AAS (FLA-10, Nippon Jarrell Ash), and at
$285.2 \mathrm{~nm}$ for $\mathrm{Mg}, 422.7 \mathrm{~nm}$ for $\mathrm{Ca}, 589.0 \mathrm{~nm}$ for $\mathrm{Na}$ and $766.5 \mathrm{~nm}$ for $\mathrm{K}$ by use of a flame AAS (AA-1, Nippon Jarrell Ash).

\section{Direct $A A S$ analysis with solid sampling technique}

About $1 \mathrm{mg}$ of milk powder was heated in the graphite furnace and analyzed by AAS with a Shimadzu/Grün SM-30 under suitable experimental conditions. The standard materials used were BCR Milk Powder, NIST Bovine Liver and NIST Citrous Leaves.

All reagents used were of analytical reagent grade.

\section{Results and Discussion}

The results of the determination of copper and zinc in

Table 1 Summary of wet ashing methods

\begin{tabular}{|c|c|c|c|c|c|}
\hline & Sample/g & Reagents & Vessel & Heating method & Commercial apparatus \\
\hline 1 & $5-10$ & $\begin{array}{l}\mathrm{HNO}_{3}-\mathrm{HClO}_{4} \\
\mathrm{HNO}_{3}-\mathrm{H}_{2} \mathrm{O}_{2}\end{array}$ & tall beaker & hot plate & \\
\hline 2 & $5-10$ & $\begin{array}{l}\mathrm{HNO}_{3}-\mathrm{HClO}_{4} \\
\mathrm{HNO}_{3}-\mathrm{H}_{2} \mathrm{O}_{2}\end{array}$ & $\begin{array}{l}\text { borosilicate } \\
\text { glass bottle }\end{array}$ & microwave & Quick digester QD-1 \\
\hline 3 & $\begin{array}{l}0.5 \text { (dry) } \\
1 \text { (wet) }\end{array}$ & $\mathrm{HNO}_{3}-\mathrm{H}_{2} \mathrm{O}_{2}$ & Teflon bottle & microwave & $\begin{array}{l}\text { Microwave Digestion Floyd } \\
\text { RMS-50 }\end{array}$ \\
\hline 4 & $\begin{array}{l}0.5 \text { (dry) } \\
3-5 \text { (wet) }\end{array}$ & $\mathrm{H}_{2} \mathrm{SO}_{4}-\mathrm{H}_{2} \mathrm{O}_{2}$ & glass flask & extreme IR light & Digesdahl 20 \\
\hline 5 & 0.5 (dry) & $\mathrm{HNO}_{3}-\mathrm{HClO}_{4}$ & Teflon crucible & electric oven & Uni-seal decomposition vessel \\
\hline
\end{tabular}

Table 2 Copper contents in several foods $(\mu \mathrm{g} / \mathrm{g})$

\begin{tabular}{lcccc}
\hline \multirow{2}{*}{ Sample } & \multicolumn{4}{c}{ Ashing method } \\
\cline { 2 - 5 } & Dry ashing & Tall beaker $\mathrm{HNO}_{3}-\mathrm{H}_{2} \mathrm{O}_{2}$ & Teflon crucible $\mathrm{HNO}_{3}-\mathrm{HClO}_{4}$ & $\mathrm{QD}^{-1} \mathrm{HNO}_{3}-\mathrm{HClO}_{4}$ \\
\hline Adzuki beans & 5.50 & 8.50 & 5.63 & 7.76 \\
Pumpkin & 0.50 & 0.50 & 0.52 & 0.57 \\
Carrot & 0.65 & 0.77 & 0.72 & 0.79 \\
Cucumber & 0.37 & 0.37 & 0.39 & 0.64 \\
Head lettuce & 0.67 & 0.55 & 0.69 & 0.65 \\
Yamanoimo & & & 0.67 & 0.23 \\
Onion & & & 0.55 & 0.52 \\
White bread & 0.90 & 1.33 & 0.96 & 1.33 \\
Skim milk & & & & 0.18 \\
\hline
\end{tabular}

Table 3 Zinc contents in several foods $(\mu \mathrm{g} / \mathrm{g})$

\begin{tabular}{lccccc}
\hline \multirow{2}{*}{ Sample } & \multicolumn{5}{c}{ Ashing method } \\
\cline { 2 - 6 } & Dry ashing & Tall beaker $\mathrm{HNO}_{3}-\mathrm{H}_{2} \mathrm{O}_{2}$ & Teflon crucible $\mathrm{HNO}_{3}-\mathrm{HClO}_{4}$ & $\mathrm{QD}^{-1} \mathrm{HNO}_{3}-\mathrm{HClO}_{4}$ \\
\hline Adzuki beans & 15.87 & 18.0 & 1.87 & 1.48 \\
Pumpkin & + & 0.78 & 329 & 0.96 \\
Carrot & + & 0.79 & 362 & 0.33 \\
Cucumber & + & 11.6 & 1.42 & 0.23 \\
Head lettuce & + & 0.03 & + & 0.33 \\
Yamanoimo & + & & 41 & 0.31 & 2.22 \\
Onion & & 1.63 & 255 & 0.77 \\
White bread & 4.99 & 9.88 & & 2.7 \\
Skim milk & & & & \\
\hline
\end{tabular}


Table 4 Content of zinc in milk powder $(\mu \mathrm{g} / \mathrm{g})$

\begin{tabular}{ccccc}
\hline Sample & \multicolumn{2}{c}{ Ashing by } & Direct AA & $\begin{array}{c}\text { Certified } \\
\text { value }\end{array}$ \\
\cline { 2 - 3 } & QD-1 & RMS-150 & & 50 \\
\hline BCR-M $^{\mathrm{a}}$ & 50 & 55 & & 50 \\
Milk-M $^{\mathrm{b}}$ & 27 & 33 & & \\
Milk-Y $^{\mathrm{c}}$ & 26 & 33 & $3.5^{\mathrm{d}}, 3.2^{\mathrm{e}}, 2.9^{\mathrm{f}}$ & 26 \\
\hline
\end{tabular}

a. BCR Milk Powder (CRM 151).

b, c. Milk powder for infant.

d. Value was obtained using Milk Powder (CRM 151).

e. NIST Bovine Liver (SRM 1577a) as a standard.

f. Value was obtained using NIST Citrous Leaves (SRM 1572) as a standard.

several foods obtained with various digestion methods are shown in Tables 2 and 3. ${ }^{6}$ The contents of copper in food samples obtained by the four ashing methods almost coincided, but zinc contents varied widely. This may be caused by the loss of zinc during the ashing or by some contamination. In order to investigate a suitable ashing method for zinc, ashing methods by use of microwave and extreme IR were examined.

The results of the determination of zinc in biological materials obtained after the wet ashings by the Quick Digester QD-1 (closed system) and the Microwave Digestion Floyd RMS-150 (open system) are shown in Table 4 , along with the analytical values obtained by direct AAS with solid sampling system and the certified values. The determination of zinc was usually carried out by ashing with an open system and the results obtained by QD-1 seemed to be better. But zinc might be lost during ashing by QD-1, and the slightly higher values obtained by RMS-150 seemed to be close to the real values. The determination of zinc in Milk-Y was carried out by the direct AAS. Three kinds of standards were used for preparing the calibration curves for the determination of zinc. Zinc could be determined by the direct AAS, but the selection of the suitable standard materials is important to obtained accurate values.

The results of the determination of several elements in NIST Bovine Liver and NIST Citrous Leaves by the IR ashing with Digesdahl 20 are shown in Table 5. The analytical values obtained almost coincided with the certified values.

The dry ashing was simple, but some volatile elements might be lost. The method is well suited to be applied to the determination of nonvolatile elements such as copper in the food.

The wet ashing methods described in this paper are suitable for AAS. The Teflon crucible and the tall
Table 5 Determination of the several elements in standard biological materials by IR ashing-AAS

\begin{tabular}{|c|c|c|c|c|c|c|}
\hline \multirow{3}{*}{ Sample } & & \multicolumn{5}{|c|}{ Element } \\
\hline & & \multicolumn{2}{|c|}{$\%$} & \multicolumn{3}{|c|}{$\mu \mathrm{g} / \mathrm{g}$} \\
\hline & & $\mathbf{K}$ & $\mathrm{Na}$ & $\mathrm{Mg}$ & $\mathrm{Fe}$ & $\mathrm{Cu}$ \\
\hline \multirow[t]{2}{*}{ NIST-Ba } & Certified value & 0.966 & 0.243 & 600 & 194 & 157 \\
\hline & Found & 1.02 & 0.237 & 510 & 240 & 157 \\
\hline \multirow[t]{2}{*}{ NIST-C ${ }^{b}$} & Certified value & 1.82 & 0.016 & 5800 & 90 & 16.5 \\
\hline & Found & 1.78 & 0.011 & 5600 & 90 & 16.1 \\
\hline
\end{tabular}

a. NIST Bovine Liver (SRM 1577a).

b. NIST Citrous Leaves (SRM 1572).

beaker methods, however, are not recommended for the analysis of the foods, because of the complicated chemical pretreatment.

The wet ashing methods by extreme IR and microwave (QD-1, RMS-150 and Digesdahl 20) gave satisfactory results. The QD-1 method is especially recommended, because about $10 \mathrm{~g}$ of food sample can be digested at a time.

Consequently, for AAS determination, the digestion by Digesdahl 20 using extreme IR was the most convenient because of the ease of temperature control and pretreatments.

\section{References}

1. T. Ohara, H. Iwao and T. Suzuki, "Syokuhinbumseki Handbook (Food Analysis Handbook, in Japanese)", p. 252, Kenpakusha, Tokyo, 1969.

2. The Association of Official Analytical Chemists, "Official Methods of Analysis of the Assoc. Offic. Anal. Chemists", 14th ed., pp. 40, 305, 310, 432, Assoc. Offic. Anal. Chemists, Inc., Arlington, 1984.

3. K. Fuwa, S. Shimomura and S. Toda, "Saishin Genshikyuko Bunseki I (New Atomic Absorption, in Japanese)", pp. 245, 248, Hirokawa, Tokyo, 1980.

4. K. Yasuda and N. Hasegawa, "Genshikyuko Bunseki (Atomic Absorption Analysis, in Japanese)”, p. 205, Kodansha, Tokyo, 1972.

5. Nagahara, H. Iwao and S. Kubo, "Shokuhin Bunsekiho (Food Analysis, in Japanese)", p. 151, Shibata, Tokyo, 1988.

6. Y. Ishii, Bull. Mukogawa Women's Univ., 32, 1 (1984).

(Received November 5, 1991)

(Accepted April 9, 1992) 